\title{
O PRESENTE COMO VIVENCIA EXTRACOTIDIANA: PERFORMANCE E REFLEXÃO.
}

\author{
Maria Betânia Silveira ${ }^{1}$ \\ Doutoranda PPGT - CEART /UDESC. \\ betapi57@hotmail.com
}

\section{PRESENTE NA CIDADE: RELATO E REFLEXÃO}

Aceita o presente? é o desdobramento, acontecido em 2011, da ação realizada no segundo semestre de 2010, denominada Aceita um presente?. O trabalho que inclui as duas versões encontra no centro da cidade de Florianópolis, em Santa Catarina, Brasil, o seu campo de atuação.

\footnotetext{
${ }^{1}$ MARIA BETÂNIA SILVEIRA (Natural de Belo Horizonte, MG. Vive e trabalha em Florianópolis, SC), possui graduação em Psicologia pela PUC de Minas Gerais (1982), especialização em Cerâmica pela Universidade de Passo Fundo/ RS (1997) e mestrado em Poéticas Visuais pela ECA/USP-SP (2007). Atualmente cursa doutorado em Artes Cênicas (CEART/UDESC-Fpolis) onde investiga territórios de fronteira entre Artes Visuais, Cerâmica Artística e Artes Cênicas. É artista plástica e professora de cerâmica desde 1988, tendo ministrado aulas por seis anos (até 2011) no Centro de Artes da Universidade do Estado de Santa Catarina, nos cursos de bacharelado e licenciatura em Artes Visuais. Também atuou, por doze anos, como orientadora da oficina de cerâmica do Departamento Artístico Cultural da Universidade Federal de Santa Catarina, em cursos de extensão e, igualmente, na oficina de cerâmica do Centro Integrado de Cultura $(\mathrm{CIC})$, ambos em Florianópolis. Tem experiência na área de Artes, com ênfase em Escultura, atuando principalmente nos seguintes temas: cerâmica, escultura, arte contemporânea, instalação, multimídia e performance. Desde 1988 vem se apresentando em exposições individuais, coletivas e Salões Nacionais e Internacionais de Arte e de Cerâmica Artística, expondo seu trabalho nacional e internacionalmente. Nos últimos anos foi selecionada pelo I e III Salão Nacional de Cerâmica de Curitiba de 2006 e 2010, respectivamente, e convidada a apresentar palestras sobre arte e cerâmica em ambos os eventos paralelos de mesma época, I e III Congresso Nacional de Cerâmica. Desde 1991 participa de Congressos e Simpósios Nacionais e Internacionais como participante e palestrante, tendo apresentado palestras em Cuba, Turquia e Suécia, países onde também se apresentou em exposições coletivas e individual. Possui várias publicações na área da cerâmica e da performance. Recebeu vários prêmios ao longo de sua carreira e Menção Honrosa na Bienal Internacional de Cerâmica Artística de Aveiros de 2009, em Portugal. Em março de 2012, apresenta 0 artigo "Paso Doble: a argila como protagonista em territórios de fronteira entre artes visuais e artes cênicas" no III Congresso Internacional Criadores Sobre outras Obras - CSO'2012. Faculdade de Belas-Artes da Universidade de Lisboa Centro de Investigação e de Estudos em Belas-Artes - tendo seu texto publicado em Atas do Congresso.
} 


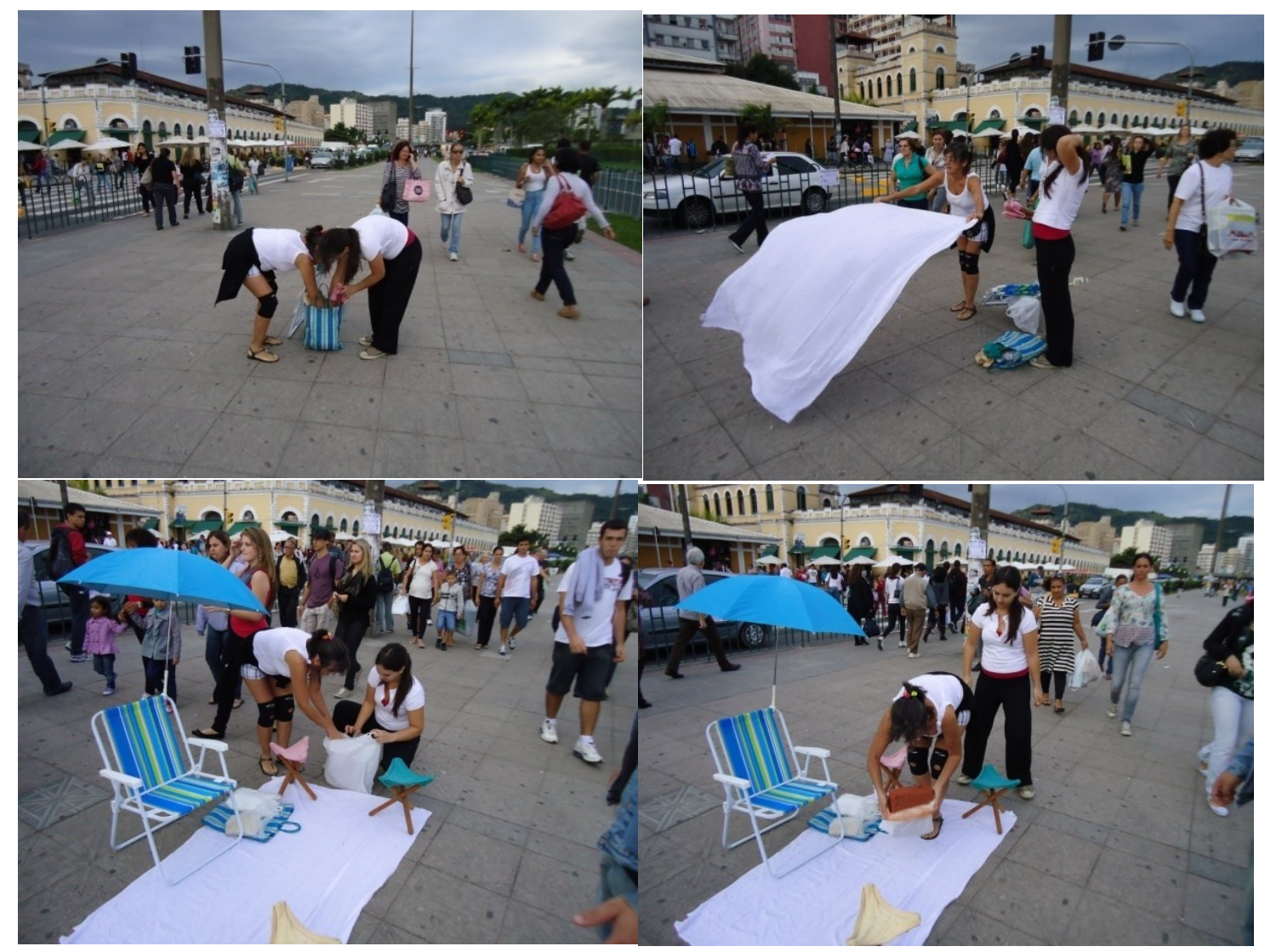

Figs. 01, 02, 03 e 04 - Aceita um presente? Betânia Silveira e Patrícia Silveira, Florianópolis, 2010.

Fonte: acervo pessoal

A intervenção se deu como performance desde a primeira versão - Aceita um presente? - realizada por Betânia Silveira e Patrícia Silveira. Como a anterior, a performance Aceita 0 presente? contou com a atuação de dois performers e suas ações sobre um corpo objetual de argila que era ofertado, numa abordagem direta, aos transeuntes, a quem se indagava:

Aceita o presente?

Pode-se notar pela troca do artigo indefinido - um - pelo artigo definido - 0 - uma modificação significativa no segundo evento, expressa em seu sentido poético, assim como na própria configuração da experiência proposta e vivenciada, que ora relatamos e desenvolvemos esta reflexão. 
Neste trabalho, o presente é conceito que carrega ambiguamente dois sentidos. É advérbio de tempo dirigido ao aqui e agora da ação feita no ato da palavra que oferta o mimo, este sim, um objeto pontual concreto, fruto das relações de contato entre artista e matéria, para ser objeto a ser doado e veículo de comunicação com o outro que transita pelas ruas do centro da cidade. Sendo assim, o presente é o momento de inter-relação e é, também, um objeto simbólico, que subsiste como testemunho de um fato passado, um dispositivo grávido de várias temporalidades, pois carrega em sua essência o passado, naquilo que foi essa vivência, e o futuro como potencialidade. Virtualidade esta, que possui em seu cerne outro presente guardado no por vir. Portanto, neste momento seguinte, o objeto de argila que foi ofertado como presente é, simbolicamente, a memória daquilo que se tornou passado e a possibilidade de um novo presente.

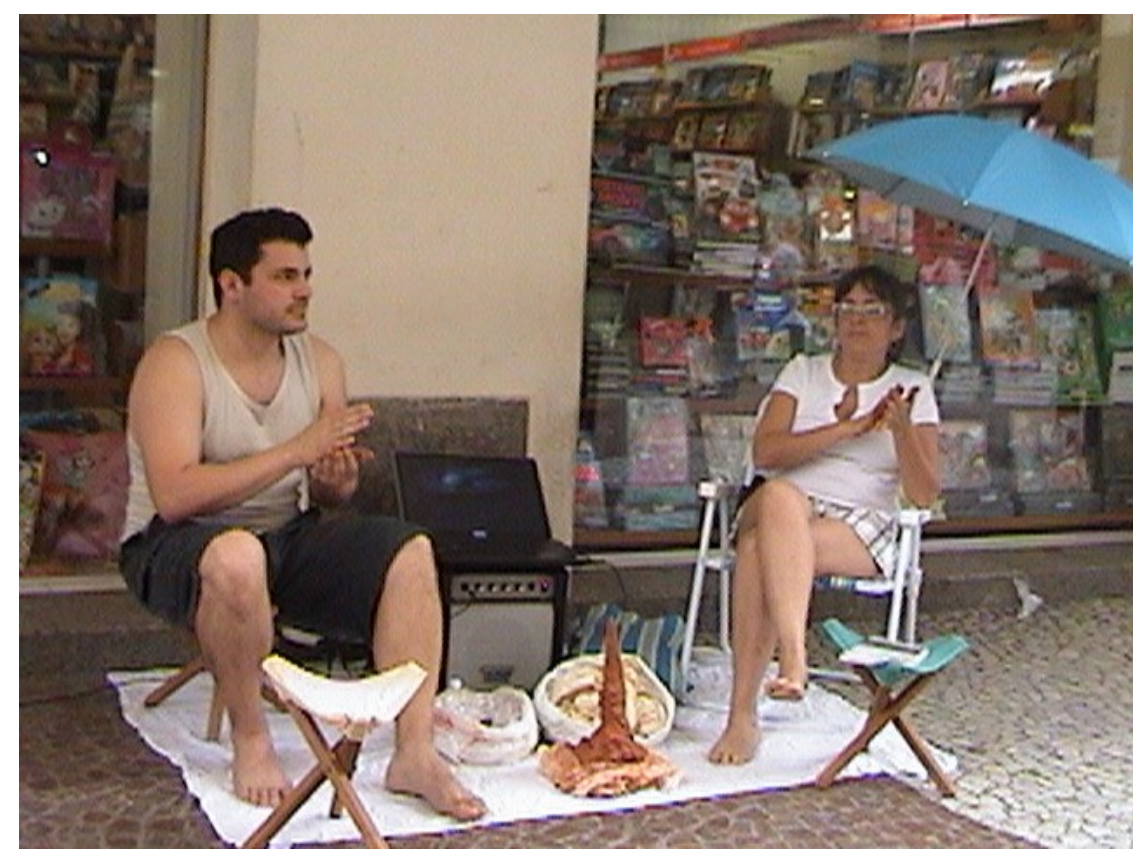

Fig. 05 - Aceita o presente? Betânia Silveira e Eder Sumariva Rodrigues, Florianópolis, SC Fonte: acervo pessoal

Desta vez, a dupla de performerse formou com uma mulher e um homem, o que promoveu outras aproximações e modificou, ao longo do processo do fenômeno, em relação à ação passada, na qual trabalhamos em dupla de mulheres, o tipo de frequência de transeuntes que se relacionou com os performes.

Embora nesse trabalho, não fosse objetivo investigar questões de gênero e, portanto, sem desenvolver aprofundamentos reflexivos nesse sentido, observamos que a presença da 
figura masculina em cena parece ter facilitado à aproximação dos homens, pois a procura deles por contato e respostas, que esclarecessem dúvidas e curiosidade, foi bem maior e, mais constantemente, dirigida ao performer Eder Sumariva.

Mantivemos, da performance anterior, para a cena atual o kit cadeira com guarda sol, banquinhos, bolsa com argila e saquinhos de plástico para acolher as peças modeladas e ofertadas como presente.

À cena comum de se ver, à borda do mar - cadeira de praia com guarda sol sobre uma canga, corpos mais expostos em sua superficialidade táctil, com a pele essa fronteira de contato e percepção do mundo relativamente desnuda, se acrescentou, desta vez, equipamentos eletrônicos de vídeo e áudio que referendavam outras paragens e buscavam excitar além da visibilidade, também, o sentido auditivo, criando camadas paralelas de realidade, participando do cenário como um elemento que proporcionava outro tipo de experiência, desdobrando as possibilidades da cena de tocar e atrair o público, compondo estratégias de sedução para capturar os pedestres através de outras potencialidades de percepção, que nossos corpos superficiais e sensoriais possuem.

O vídeo mostrava imagens de uma viagem recente ao Peru e uma escalada nas paisagens de Machu Pichu, imagens de belíssima natureza se entrelaçando a respiração forte de um corpo em esforço, a um poema de Cecília Meirelles e a música instrumental de John Coltrane. As imagens do vídeo apresentavam outro tempo e lugar, convite à contemplação que ativava a memória daqueles que em suas próprias vidas estiveram por aquelas paisagens ou outras semelhantes. 0 som que emitia o vídeo capturava o passante, cujo sentido auditivo e gosto pela música serviram-Ihe como leit motiv para o estabelecimento deste contato. Esses elementos eram fios tecendo materialidades diferentes propondo outras experiências e gerando outros sentidos. 


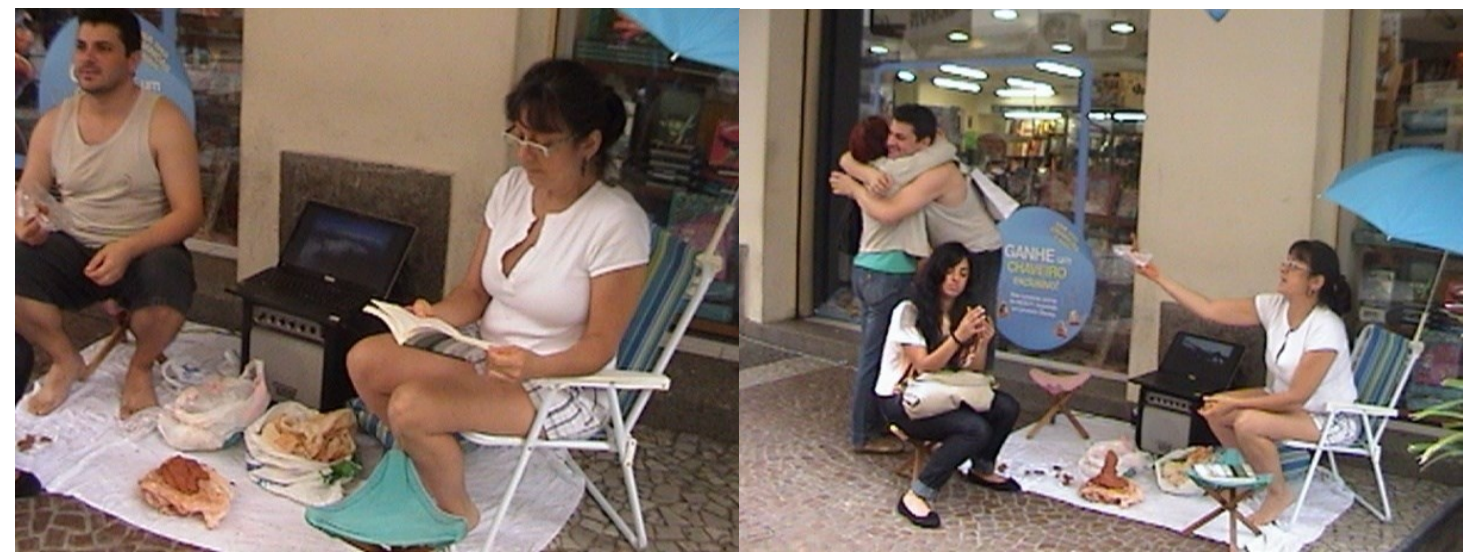

Figs.06 e 07- Aceita o presente? Betânia Silveira e Eder Sumariva Rodrigues, Florianópolis, SC. Fonte: acervo pessoal da autora.

Além do audio e vídeo, foi acrescentado à oferta da porção de argila certos elementos como a leitura de poemas de Cecilia Meirelles e a surpresa de um abraço (proposição de Elder), doações de ordem imaterial que enriqueciam o conjunto dos presentes materiais, personificados pelo torrão de argila, ora modelado em figuras variáveis, ora apenas apertado pela preensão palmar, referência ao trabalho plástico, de nome "Amassadinhos", da artista contemporânea brasileira Celeida Tostes. A cena se completava com a presença dos performers desenvolvendo suas ações, conjunto que, não exatamente, se trata de uma representação, mas que oscila entre a realidade da presentação e o ficcional que se aparenta quando se desloca a ambiencia própria de um certo lugar para outro onde ela se torna inaudito.

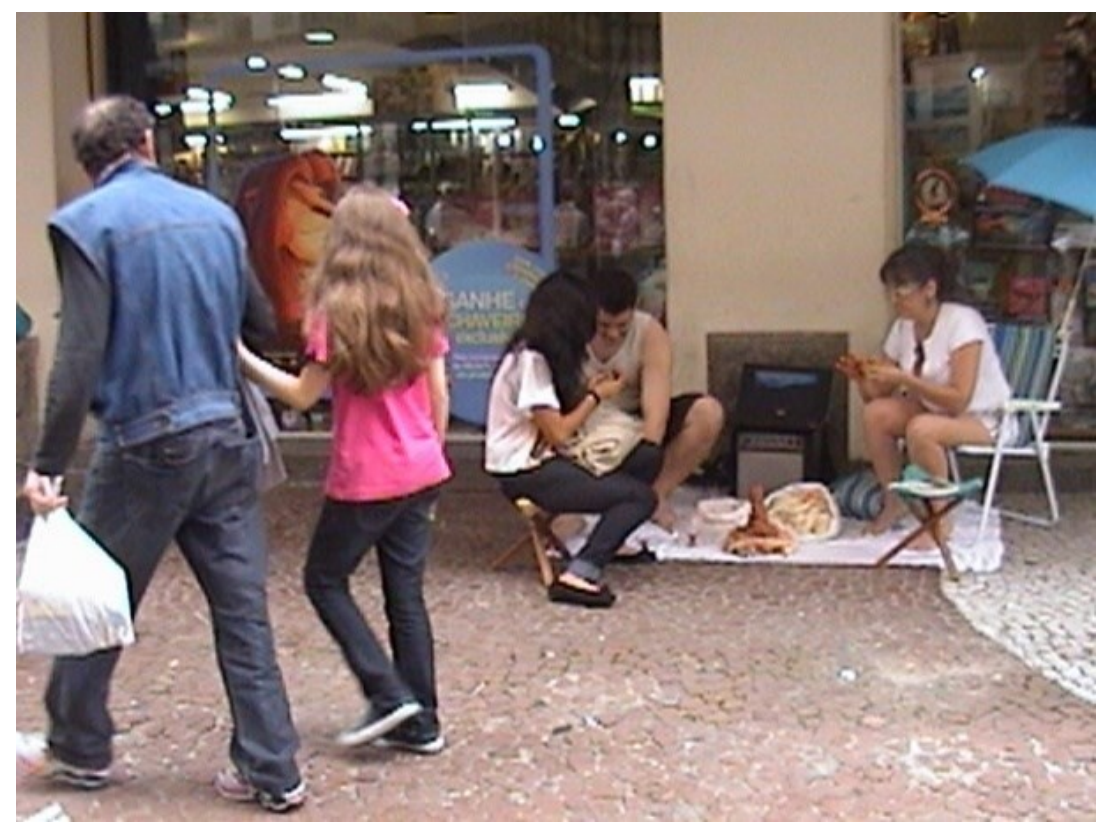

Fig. 08- Aceita o presente? Betânia Silveira e Eder Sumariva Rodrigues, Florianópolis, SC

Fonte: acervo pessoal da autora

Revista "O Teatro Transcende" do Departamento de Artes - CCE da FURB - ISSN 2236-6644 - Blumenau, Vol. 18, № 1, p. 03 - 18, 2013 
Durante três manhãs, nos instalamos no centro da cidade, em frente a uma livraria, que nos cedeu seus pontos de eletricidade para fazermos funcionar o vídeo que acontecia, sem interrupção e paralelamente a ação dos dois integrantes da performance.

Esta versão foi repetida por três manhãs, sempre no mesmo lugar e hora. Mas como já disse o Filósofo "ninguém se banha duas vezes na água do mesmo rio2", mesmo que, repetindose o local, a cena proposta como espaço potencial e a mesma ideia de modelar presentes de argila crua para ofertá-los aos passantes, a cada novo dia, vimos surgir uma nova peformance. Embora seu programa fosse praticamente o mesmo - montar uma cena de praia no terreno árido de cimento, em meio ao burburinho do centro da cidade e ofertar o presente - eram sempre outras as pessoas que transitavam e nossos corpos reatualizados, também eram outros. Nós mesmos modificados pelas vivências anteriores éramos novos. Como nos diz Erika FischerLichte (2008) em The transformative power of performance, o poder de transformação de uma performance se estende e modifica todos os envolvidos, atuantes e audiência. Ambos podem, inclusive, vivenciar a inversão de papeis, na qual o espectador passa a ser 0 atuante, contemplado por outros espectadores, e o performer pode se transformar no alvo de sua ação, como aconteceu no caso da performance Lips of Thomas de Marina Abramovic e, também, em "Aceita o presente?" quando fomos surpreendidos por adolescentes que voltaram no dia seguinte, trazendo-nos de presente a modelagem que fizeram com o objeto de argila que ganharam no dia anterior, ou ainda, no caso de outra jovem que, na manhã seguinte de nosso primeiro contato, voltou até nós e pediu-nos para sentar-se conosco, acompanhando-nos por toda uma manhã em nosso evento, oferecendo-nos como presente a sua companhia e o que produziu com a argila no período em que fez parte da cena.

${ }^{2}$ Heráclito de Éfeso - (Éfeso, aprox. 540 a.C. - 470 a.C. $)$ Filósofo pré-socrático considerado o "pai da Revista "O Teatro Transcende" do Departamento de Artes - CCE da FURB - ISSN 2236-6644 - Blumenau, Vol. 18, № 1, p. 03 - 18, 2013 


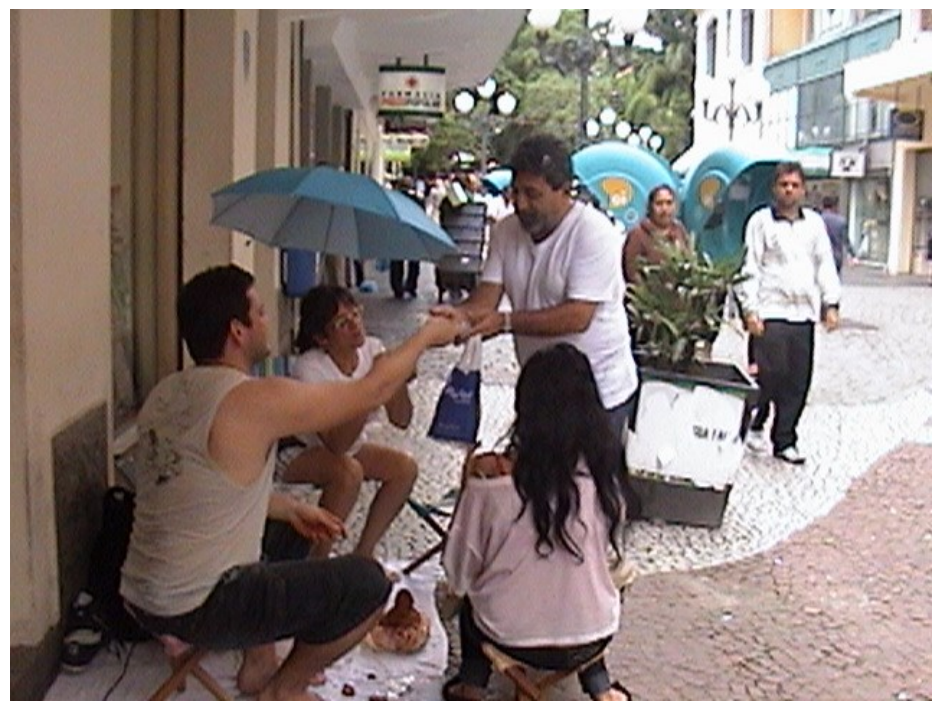

Fig. 09 - Aceita o presente? Betânia Silveira e Eder Sumariva Rodrigues, Florianópolis, SC. .Fonte: acervo pessoal da autora.

Embora, o fato de permanecer por horas modelando pequenas quantidades de argila $\mathrm{e}$ doá-las como presente seja uma realidade, que mais parece representação, nada havia ali a ser interpretado, apenas experenciado. Porem, a realidade toma o lugar oscilante de uma ficção, pois não parece real alguém presentear estranhos sem pedir nada em troca No mundo contemporâneo tudo se permuta por dinheiro. No entendimento breve das pessoas que rapidamente passam, não há verdade em uma oferta desinteressada, assim sendo, para muitas delas seria possível que, após aproximarem-se da cena em andamento, fossem surpreendidas por alguma proposta de contrapartida.

Ao se depararem com a realidade extracotidiana de uma doação desinteressada surpreendiam-se e, imediatamente, pareciam acessar dentro de si mesmas o prazer de viver as interrelações humanas, sociais e culturais, momento de auto conscientização vivido dentro da ótica de que a vida também pode ser boa.

Desta forma, todos estavamos envolvidos naquela situação e, de espectadores, os indivíduos passavam a ser cocriadores da performance. A eles, com seus desejos interiores e escondidos, seguiam os performes no encaminhamento das ações. Os sujeitos, no momento que interagem 
com os performers e passam a fazer parte da performance, adicionam a ela suas ações e thes acrescenta seus sentidos modificando, também, a nós performers.

Criou-se, no processo, um campo magnético de afeições e aproximação, borrando os limites da cena teatral. Nesses momentos arte e vida se confundiam.

A idéia de facilitar que as pessoas pudessem carregar a argila, mantendo-a úmida devido à embalagem plástica que fornecíamos, tinha como objetivo criar uma possibilidade de desdobramento daquele instante. Em outro tempo e lugar, as pessoas, novamente, poderiam entrar em contato com aquele material que, provavelmente, pelo movimento no trajeto urbano, já disforme na bolsa, no bolso ou nas mãos, poderia ter se tornado, como uma mancha pode ser, 0 instigador para a modelagem de outras imagens.

Leonardo Da Vinci nos fala sobre o valor das manchas para nossa imaginação. Elas podem ser fontes de criação de novas formas, nelas podemos projetar tanto nossos demônios, quanto nossas miragens e, assim, enriquecermos inventivamente nosso universo de criações:

\begin{abstract}
Não desprezem a minha opinião quando eu vos lembro que não deveria ser difícil parar, vez por outra, e olhar as manchas nas paredes, ou as cinzas de uma lareira, ou as nuvens, ou a lama, ou coisas parecidas em que, se considerá-las bem, poderão encontrar idéias realmente maravilhosas. A mente de um pintor é estimulada por novas descobertas: a composição de batalhas entre animais e entre homens, várias composições de paisagens e coisas monstruosas como diabos e criaturas semelhantes, que devem trazer-vos honra, pois a mente é estimulada a novas invenções por meio das coisas obscuras. (Tratado sobre a pintura, Codex Urbinas Latinus 1270 citado por ALPHEN, 2006, p.93).
\end{abstract}

O presente modelado tornado mancha no trajeto, por si só, queremos crer, já autorizaria e convidaria o imaginário do indivíduo a se expressar manipulando a argila efetivamente, livre da expectativa do olhar alheio que faz julgamentos estéticos e que precisa reconhecer nas formas produzidas, outras já conhecidas. Parte do processo, sempre velada, pois, nunca saberemos como foi, realmente, o segundo encontro do presenteado com seu presente modificado. Fato corriqueiro na arte, pois jamais sabemos o que leva consigo da obra o seu fruidor. 
Esta idéia continuava a mover-me o desejo de presentear, pois o que doamos como objeto é uma mancha ou imagem, que mesmo que concretizada na argila, possui curta duração, uma espécie de imagem mariposa da qual nos fala Didi-Huberman (2007), pois a rapidez com que sua forma se deforma, faz com que sua visibilidade não the permita ser apreendida em detalhes, como uma borboleta que voa e leva consigo seu desenhos incognitos sem deixar que os desvendemos por completo. Neste caso, mais que a imagem mariposa de Didi- Huberman, este presente se comporta como uma fenix, pois, após o desfazer de sua primeira forma, ele pode tomar outras tantas aparencias, inclusive ser somente um pequeno pedaço inutil de terra. Mesmo assim, trata-se de um signo que estará sendo ressignificado, de acordo com a subjetividade em fluxo processual constante e a interrelação com a matéria plástica, pois a argila, como excelente material projetivo que é, tambem envia pistas e mensagens que são decifradas segundo a capacidade de leitura, que a lente da realidade psíquica, emocional e cognitiva de cada um, pode proporcionar.

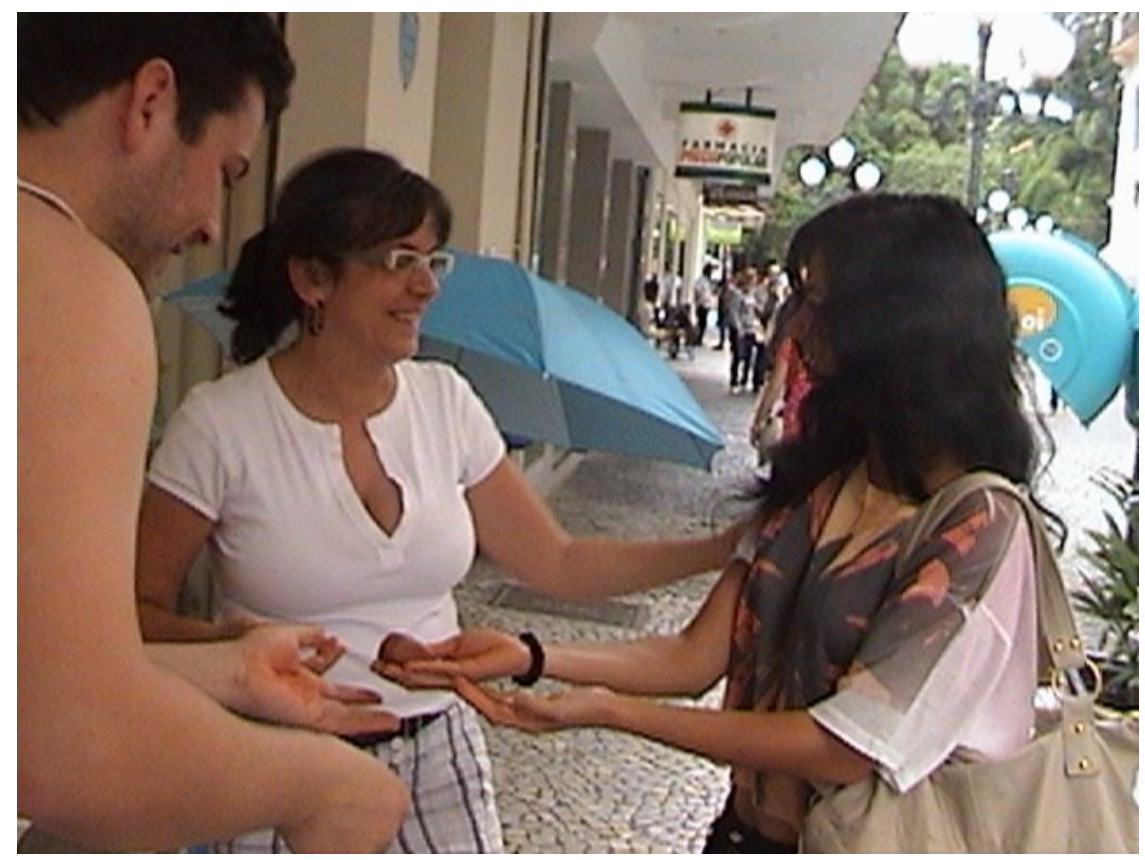

Fig. 10 - Aceita o presente? Betânia Silveira e Eder Sumariva Rodrigues, Florianópolis, SC Fonte: acervo pessoal da autora

Por outro lado, o presente se constitui da presença dos performers, cujos corpos são entendidos como fenômenos experienciados, ao invés de objetos representados para um olhar Revista "O Teatro Transcende" do Departamento de Artes - CCE da FURB - ISSN 2236-6644 - Blumenau, Vol. 18, № 1, p. 03 - 18, 2013 
contemplativo, e suas ações, que são proposições para uma experiêcia extracotidiana. Convidando as pessoas a vivenciar, através da interrelação social, seu universo imagético, sua realidade subjetiva, sem a preocupação de que fossemos compreendidos no que fazíamos como artistas, importava-nos mais a experiência que estávamos tendo e proporcionando, o que para nós fica claro que o evento da performance é mais forte que as interpretações possiveis a seu respeito e que, a materialidade de nossas ações prevalece sobre suas qualidades semióticas.

Comprometidos e engajados com 0 projeto de interceptar 0 frenético transito dos indivíduos na cidade, de certa forma, impelindo-os a transgredir a norma capitalista da rápidez, e do entendimento de que tempo é dinheiro, para experimentar e se deixar tocar por um momento de prazer e imaginação no coletivo coração da cidade, eramos todos materialidades em processo, subjetividades construindo juntos uma outra realidade. Não meramente interpretada, mas vivenciada. Tanto oferecíamos o presente tempo e o presente objeto, quanto desfrutávamos da experiência com ambos, prova vivencial do poder extenso de transformação que a performance pode promover à todos os envolvidos, modificando-os e, da mesma forma, modificando a realidade de seu momento no cotidiano.

Afinal, ficou desta experimentação, a consciência de ter vivido um momento para além do ordinário cotidiano. Os sentimentos fruidos no interjogo com o público, os sentidos gerados nesse contato, as transformações subjetivas internalizadas são ganhos imateriais que enriquecem internamente as pessoas que o vivenciaram.

Alguns tecidos foram usados para umidecer e limpar as mãos coloridas pela argila. Pintando-se com a coloração deste material, o tecido ficou marcado com os rastros concretos do processo das ações efêmeras, caracterizando-se como registro. 


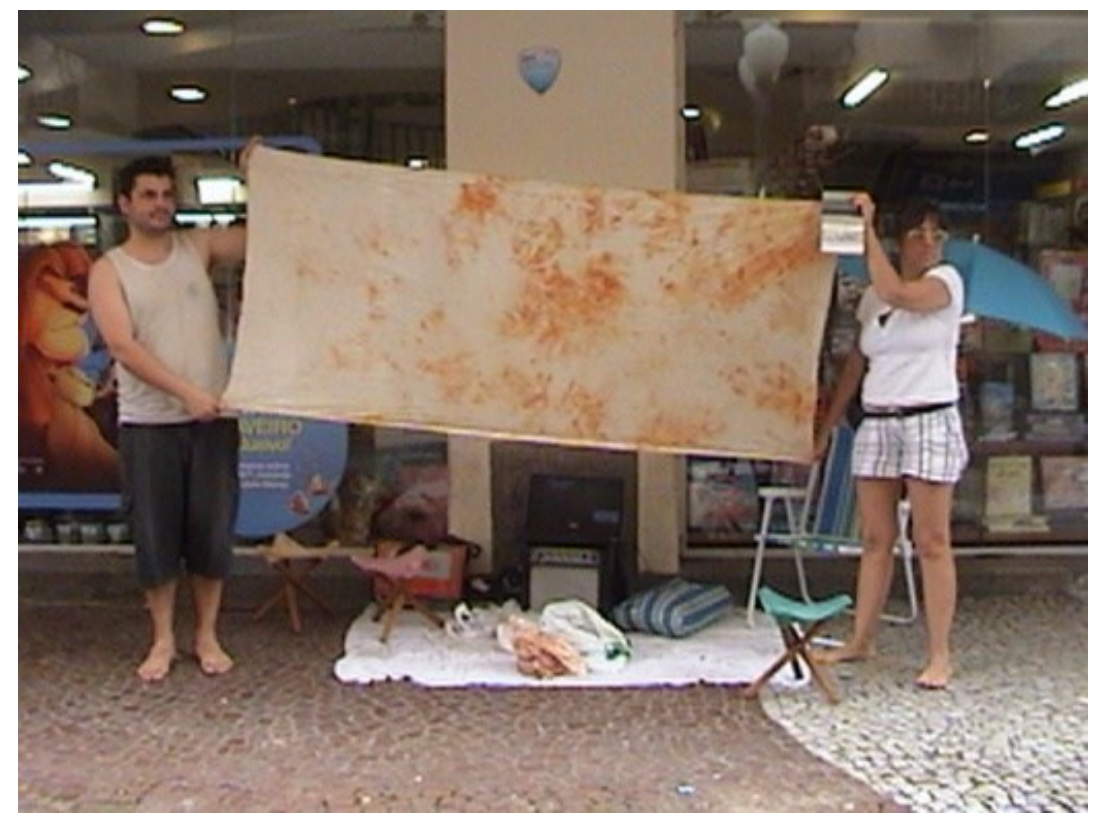

Fig. 11 - Aceita o presente? Betânia Silveira e Eder Sumariva Rodrigues, Florianópolis, SC.

Fonte: acervo pessoal da autora

As performances da segunda versão foram sempre finalizadas ao nos colocarmos de pé, segurando o tecido aberto e o livro de Cecília, cujo poema era recitado em tom ideal para ser ouvido a longa distancia, o que encobria, para os que estavam mais próximos, o ruido indistinto e constante da cidade.

O tecido aberto é elemento visual impregnado de mistério e intriga pelo valor dado a algo, aparentemente, tão insignificante como um pano sujo de terra. Ele se torna parte da poesia falada no audio visual e mais um elemento da performance.

Essa transformação do que é insignificante para um contexto de relevada importância aponta para a relatividade das verdades e dos juizos de valores. 


\section{CONSIDERAÇÕES FINAIS}

No terreno fronteiriço entre artes visuais e artes cênicas se deu a criação de eventos cuja teatralidade se instaura na imbricação de fontes variadas. 0 estabelecimento de um espaço potencial, comum a prática de Peter Brook, aliado a intenção corporificada dos performers atuando sobre um pedaço de argila, tornava-se razão de encontros e induzia o surgimento da teatralidade. Nesta presentação de sujeitos e barro, ao contato com os fruidores soma-se o olhar dos espectadores. Este olhar abre uma fenda na imagem da cena para vê-la como um objeto espetacular. Tipo de teatralidade que se dá fora dos palcos e que pode ser encontrada no cotidiano, talvez aquele tipo de teatralidade que Ferral (2000) relaciona mais à antropologia e etnologia do que ao teatro, por estar inscrita no cotidiano.

Da mesma forma, o evento inclui um artefato metamórfico de argila, próprio das artes visuais, criado para ser independente de seu criador e passivel de ser resignificado pelo outro, por meio de sua própria percepção e interpretação. Objeto que poderia ser, também, num segundo momento, remodelado pelas mãos do sujeito presenteado.

A performance Aceita o presente? trata-se de um fato processual que se dá por meio de imagem, som, ação, presença e objeto simbólico. 0 evento nasce em uma zona de contato formada por saberes transversais. Na trama que se estrutura com eles, o corpo é circuito orgânico e perceptivo - corpo de superfície e corpo recessivo aquele da "dimensão profunda da experiência abaixo da superfície da carne" (ZARRILLI, 2007, p.54) responsável pela ação que constitui a cena, na qual o fazer com a argila estimula a imaginação.

O fruidor/participador, ao parar para o apelo de uma oferta, ativa uma arma contra a domesticação. Ao mesmo tempo, vivencia um acontecimento no fato de que aceitar o presente pode levá-lo a expandir a qualidade de sua momentânea realidade, sua relação com o viver, com o acaso e com o outro, fazendo de sua existência uma experiência mais formativa e transformativa. Nesse processo, ambos, performer e espectador/participador, têm a chance de 
vivenciar um encontro no qual o real e o ficcional se contatam na cena iniciada pela ação do performer que é alternadamente ator, pois, às vezes, sentimos que até mesmo na ordem social, representamos quando saímos do nosso papel, para viver outro. $O$ fruidor, aquele que nos olha, é afetado pela ligação das idéias geradas pela imagem do que vê. Como diz Didi-Huberman (1998) em "O que vemos o que nos olha" a imagem olhada faz fissura e no olhar que vê é reconstituída e resignificada.

Nos gestos que compõe a performance é possível ver refletido cenas sociais. Ao estender a mão para ofertar o presente enviamos dúbia mensagem, pois na fenda que se abre nessa imagem mirada, poderia se ver também o ser pedinte, personagem da injustiça social, comum nas ruas das grandes cidades brasileiras. $O$ que pede a arte através de nossa ação? Possivelmente, o seu lugar no seio do povo e a sua função social.

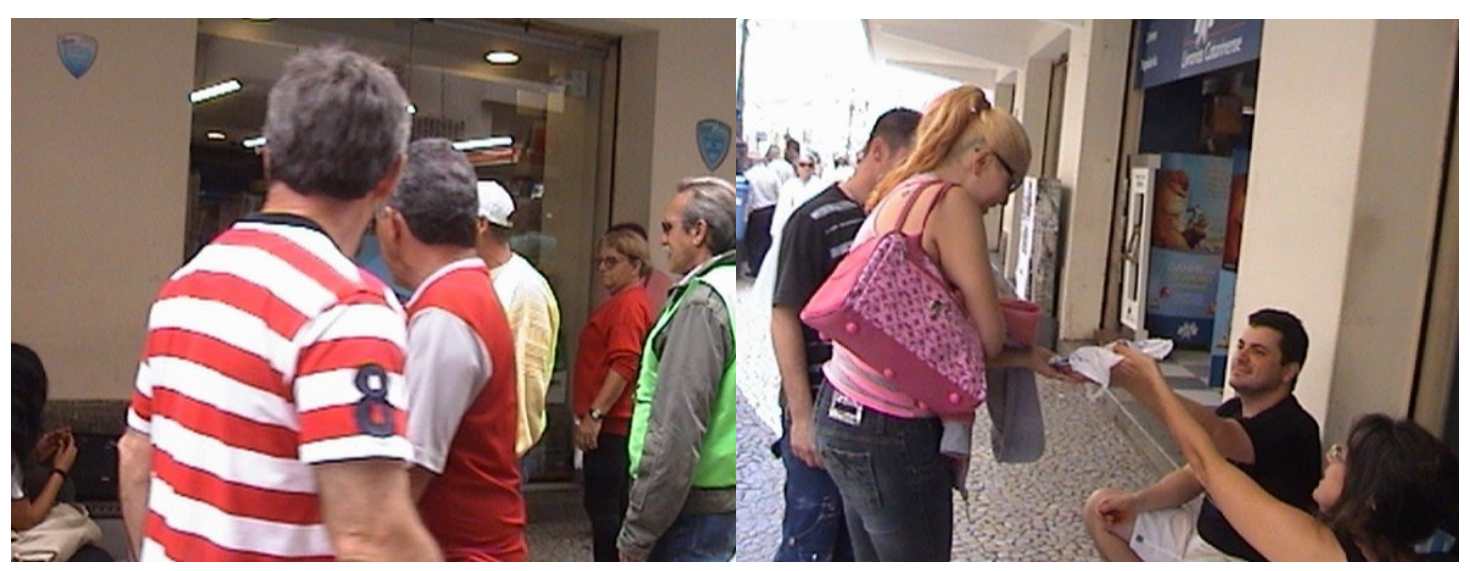

Fig. 12 e 13 - Aceita o presente? Betânia Silveira e Eder Sumariva Rodrigues, Florianópolis, SC Fonte: acervo pessoal da autora

Performers e audiência semelhantemente aceitam que uma função primária dessa atividade é precisamente o metacomentário cultural e social, a exploração do self e do outro, do mundo como experimento e de possibilidades alternativas. (CARLSON, 2009, p.221).

Em vivencias como esta que ora refletimos, por meio da interação, o sujeito sai da condição de massa humana para a de indivíduo e transita do território do publico para o privado, do anonimato quando é abordado, para a individuação ao se relacionar, pois reatualiza-se como 
indivíduo no momento em que tem sua subjetividade provocada e sua inventividade instigada pelo contato imprevisto.

Por outro lado, a proposta viabiliza a possibilidade de, também, transformar um material como a argila. Expressar-se por meio dela abre uma brecha para o imagético, que revela conteúdos internos, emocionais e culturais.

A proposta realizada no centro de Florianópolis entende a cidade com um espaço privilegiado para esse tipo de intervenção, que rompe com as convenções dos saberes específicos, que é relacional e que se utiliza mais da presentação do que da representação, embora contenha momentos de ambivalência nesse sentido. Trabalhamos com a realidade e 0 espaço humano, o externo e o interno de cada um de nós, o real e o fictício, o transito e 0 deslocamento. Nesta ação observa-se uma teatralidade expansiva já que o espectador teve a oportunidade de não ser passivo fazendo do seu igual, espectador do espectador. Trabalhamos com o acaso, o efêmero, intenções preparadas e não preparadas ${ }^{3}$ e uma pergunta performática e experimental que nos permitiu um diálogo entre vida e arte.
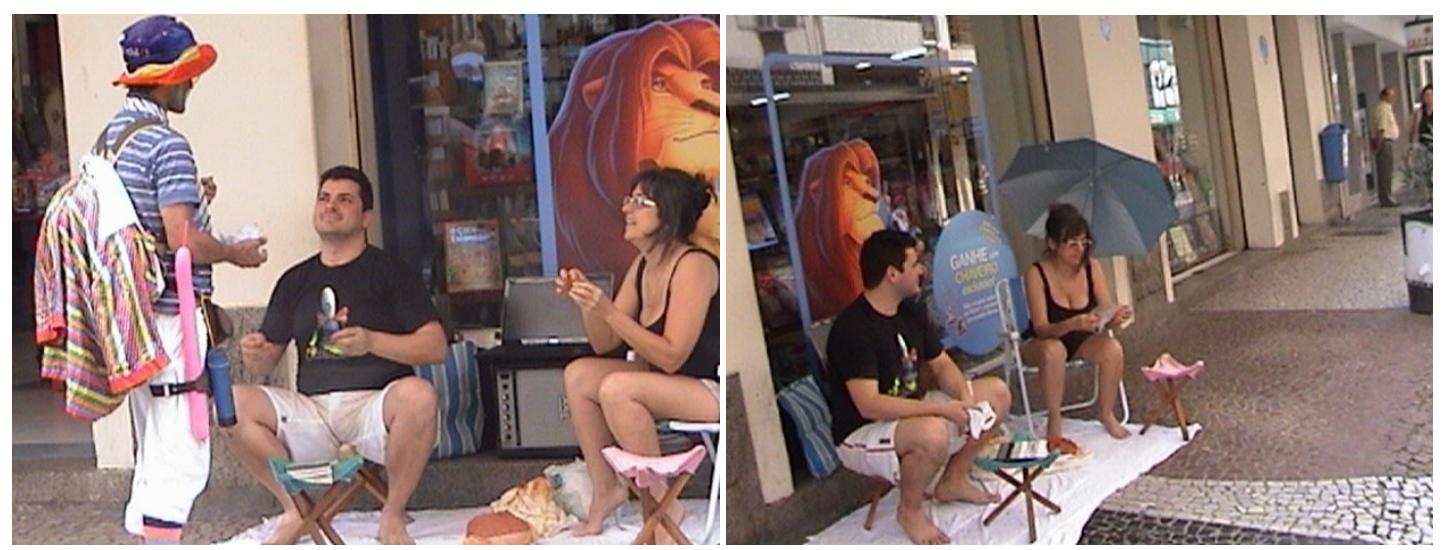

Fig. 14 e 15 - Aceita o presente? Betânia Silveira e Eder Sumariva Rodrigues, Florianópolis, SC Fonte: acervo pessoal da autora

${ }^{3}$ No sentido que Bonfitto ( explicita em A Cinética do Invisível, p.186-187 : “ Este segundo modo de intencionalidade está profundamente relacionado com a tensão entre o pessoal e o impessoal; ele emergiu dessa tensão. (...) intenções que não são preparadas foram examinadas por alguns filósofos. Merleau Ponty, por exemplo, se refere a uma espécie de intenção que não depende de decisões tomadas por alguém: 'Na medida em que eu tenho mãos, pés, um corpo, eu sustento ao meu redor intenções que não dependem de minhas decisões, e que afetam as circunstâncias em que vivo em um modo que não posso escolher.'"

Revista "O Teatro Transcende" do Departamento de Artes - CCE da FURB - ISSN 2236-6644 - Blumenau, Vol. 18, № 1, p. 03 - 18, 2013 
Vivenciar e experimentar a cena como acontecimento - presentação da ação - e verter os materiais em imagens são, também, pontos de contato entre artes visuais e artes cênicas, fronteira entreaberta na qual o corpo é espaço de criação e o espaço é corpo de criação. Imbricação por meio da qual se apresenta uma circunstância oportuna para refletirmos sobre nosso lugar e papel na sociedade e na cultura, redefinirmos a nós mesmos ao proporcionamos ao outro que, também, o faça.

\section{REFERÊNCIAS}

ALPHEN, Ernest Van. Lances de Hubert Damisch: pensando a arte na história. Revista do programa de Pós-Graduação em Artes Visuais EBA. UFRJ, 2006, p. 93 - 103.

BAITELLO, N. Corpo e imagem: comunicação, ambientes, vínculos. In: RODRIGUES, D. (Org.). Os valores e as atividades corporais. São Paulo: Summus, 2008. p. 95-112.

BARROS, Amilcar Borges de. Dramaturgia corporal: acercamiento y distanciamiento hacia la acción y la escenificación corporal. Santiago: Editorial Cuarto Próprio,2011.

BONFITTO, M. A cinética do invisível. São Paulo: Perspectiva, 2009. IV - $\mathrm{O}$ ator e o performer in Hic et nunc - entre identidades e alteridades. Inédito.

CARLSON,Marvin. Performance: uma introdução crítica. Tradução Thais Flores N. Diniz, Maria Antonieta Pereira. Belo Horizonte: Editora UFMG, 2009.

DAWSEY, John C. Victor Turner e antropologia da experiência. Revista Caderno de Campo $n^{0} 13,2005$.

DEWEY, J. Arte como experiência. São Paulo: Martins Fontes, 2010. 
DIDI-HUBERMAN, Georges. 0 que vemos, o que nos olha. Prefácio de Stéphane Huchet; Tradução de Paulo Neves. São Paulo: Ed 34, 1998. ( Coleção TRANS).

La Imagen Mariposa. Barcelona: Mudito \& Co, 2007.

FABIÃO, E. Corpo cênico, estado cênico. In: Revista Folhetim - Teatro do Pequeno Gesto, n.17, mai./ago. 2003, p. 24-33.

Performance e teatro: poéticas e políticas da cena contemporânea. In: Revista de Artes Cênicas sala preta, n.8, p.235-246. São Paulo: Departamento de Artes Cênicas, ECA/USP, 2008.

FÉRAL, Josette. Acerca de la Teatralidad: cuaderno de teatro XXI. Directión Osvaldo, 2000.

FISCHER-LICHTE, Erika. The transformative power of performance. London and New York, Routledge, 2008.

KIRBY, Michael. Acting and not-Acting. In: A Formalist Theater. Philadelphia: Univesity of Pennsylvania Press, 1987. Pp. 3-20.

PALLAMIN, Vera M. Arte urbana. São Paulo: Annablume: Fapesp, 2000.

TURNER, Victor. Dewey, Dilthey e Drama: um ensaio em antropologia da experiência (primeira parte). Tradução Herbert Rodrigues. Revista Caderno de Campo nº 13, 2005.

ZARRILLI, Phillip B. Senses and silence in actor training and performance in: The senses in performance, Sally Banes ET Andre Lepecki. NY: Routledge, 2007. 